\title{
TRANSPERICARDIAL PHRENICOTOMY FROM A DAGGER WOUND
}

\author{
BY \\ S. GOLDWATER AND S. LOCKET \\ From Oldchurch Hospital, Romford, Essex
}

(RECEIVED FOR PUbliCATION JANUARY 14, 1954)

Many examples of penetrating wounds of the heart and pericardium have been recorded (Barrett, 1950). The phrenic nerve has occasionally been divided in the neck as a result of knifing (Reichl, 1932) or of gun-shot wounds (Neuhöfer, 1922), but the literature contains no reports of injuries to the phrenic nerve in the chest in which the patient has survived. The following case is therefore of interest.

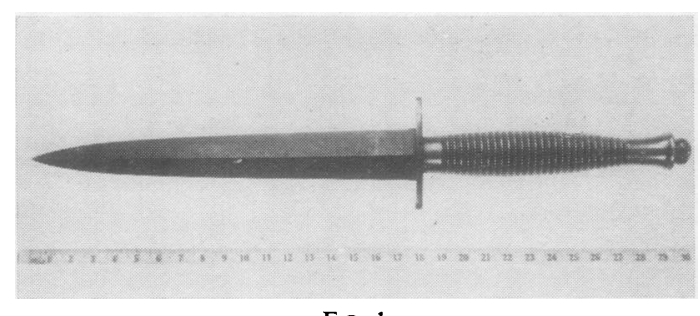

FiG. 1

Mrs. D. B., age 18, was admitted to Oldchurch Hospital on April 14, 1952, after she had been stabbed through the chest with a commando dagger (Fig. 1). She later described how her assailant seized her neck with his left hand while in his right she saw the dagger pointing towards her. She felt no pain and next remembers seeing the dagger protruding from her chest; she pulled it out and ran screaming into the street, where she collapsed. On admission she was in extremis with a barely perceptible pulse and a blood pressure too low to record. There was a penetrating wound of the skin over the lower end of the sternum just to the left of the midline. It was about $2 \mathrm{~cm}$. in length and was oblique downwards from left to right. An immediate blood transfusion was given and the patient recovered sufficiently to be removed to the ward after a few hours.

Radiographs taken the same evening and next day showed a progressive effusion into the right pleural cavity. Nearly 1.51 . of heavily blood-stained fluid was subsequently aspirated. On further radiological examination (Fig. 2) it was found that the right side of the diaphragm was raised and there was some collapse of the right lower lobe. Paradoxical movement of the right diaphragm was seen on screening.
Two months later there was some tone in the diaphragm and the lung had re-expanded (Fig. 3). By March, 1953, 11 months after the injury, the right diaphragm was moving normally but had not quite recovered its full excursion. In the meanwhile the patient had become pregnant and was normally delivered.

Electrocardiograms 36 hours after admission (Fig. 4a) showed elevation of the S-T segment in all chest leads and an inverted $\mathrm{T}$-wave in lead 3. A week later (Fig. 4b) the T-wave was inverted in leads V2 and V3, the leads over the right ventricle, but the $\mathrm{S}-\mathrm{T}$ segment was now normal. After two weeks (Fig. 4c) the E.C.G. had reverted to normal, T3 now being upright.

The QRS type of V1 lead and the QR complex in AVR indicate an unduly clockwise rotated heart with the right ventricle more anterior than usual.

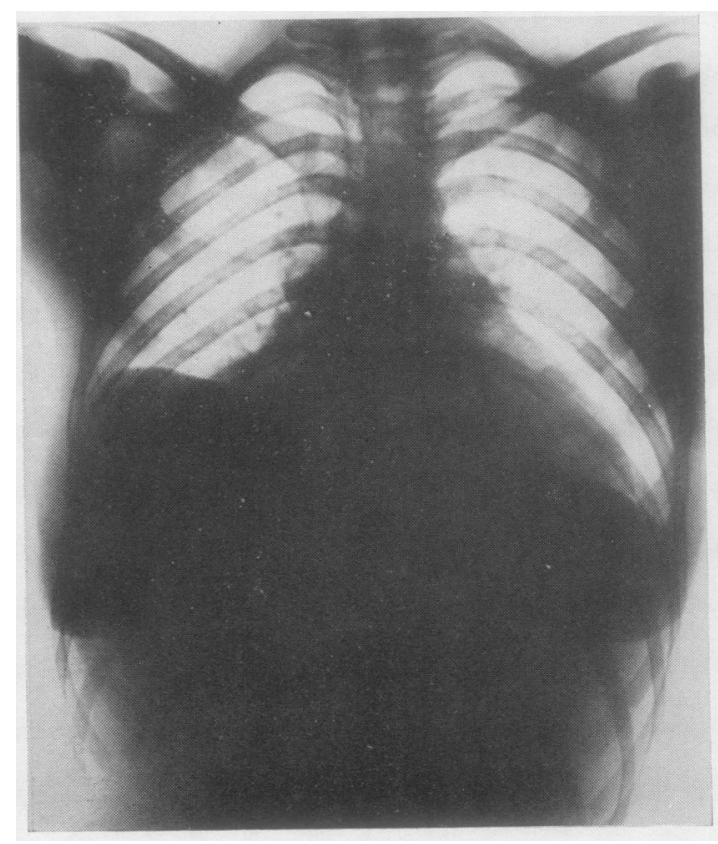

FIG. 2 


\section{Discussion}

At the time of injury the dagger was covered with blood up to the hilt, a distance of $17 \mathrm{~cm}$., and it is now possible to trace the path it is likely to have followed. As the weapon was thrust into the chest in the assailant's right hand it would have pulled the skin across the mid-line and glanced off the right border of the sternum at its lower end. At this level it would have passed through the lower right extremity of the pericardial sac, and the E.C.G. findings suggest that it also lacerated the adjacent heart-wall, namely, the right ventricle, very slightly. The phrenic nerve would then have been severed where it enters the diaphragm. The blood in the pleural cavity may have resulted from division of the pericardiophrenic vessels accompanying the nerve or from laceration of the upper surface of the diaphragm. The mediastinal veins too might have been torn. There is insufficient electrocardiographic evidence to indicate a penetrating wound of the ventricle, and in the absence of pericardial effusion it is unlikely that the blood in the pleura originated from the heart. There was

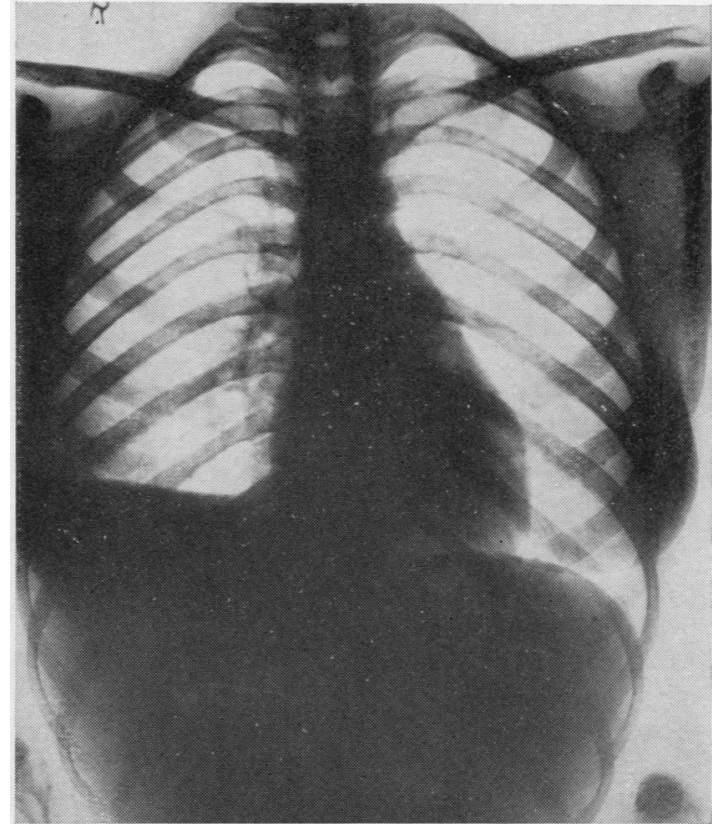

FIG. 3

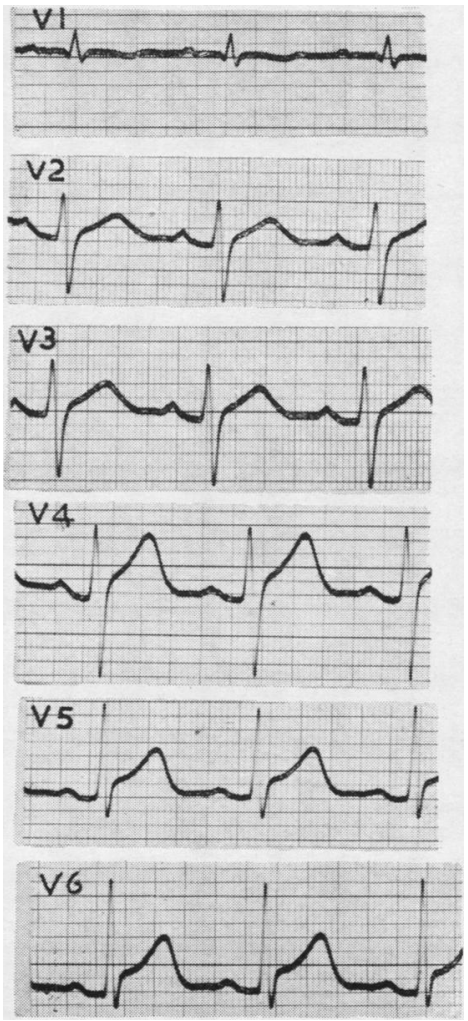

FIG. 4a

$16 / 4 / 52$
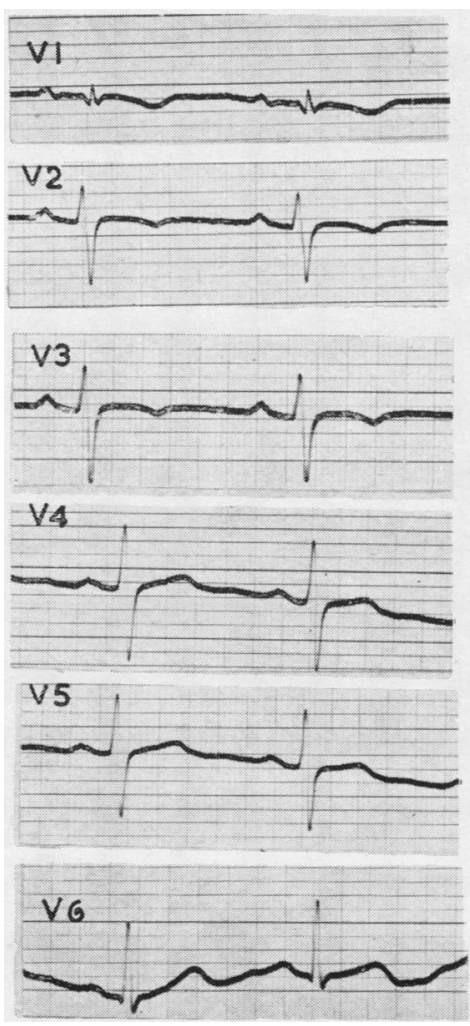

Fig. 4b

$23 / 4 / 52$
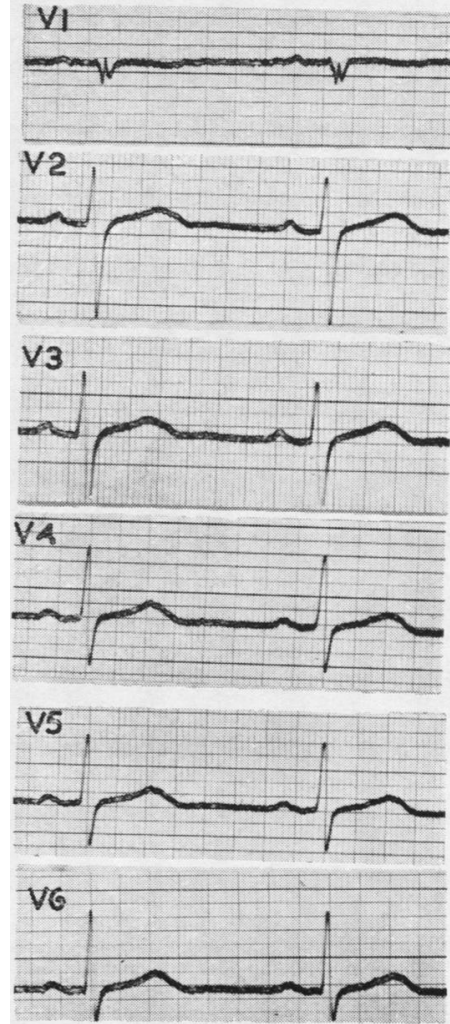

FIG. $4 c$

$30 / 4 / 52$ 


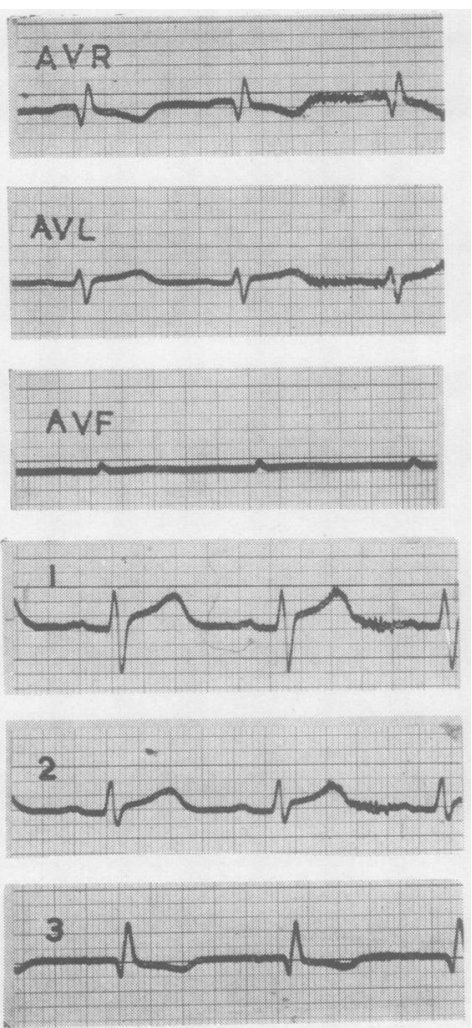

Fig. 4a

$16 / 4 / 52$

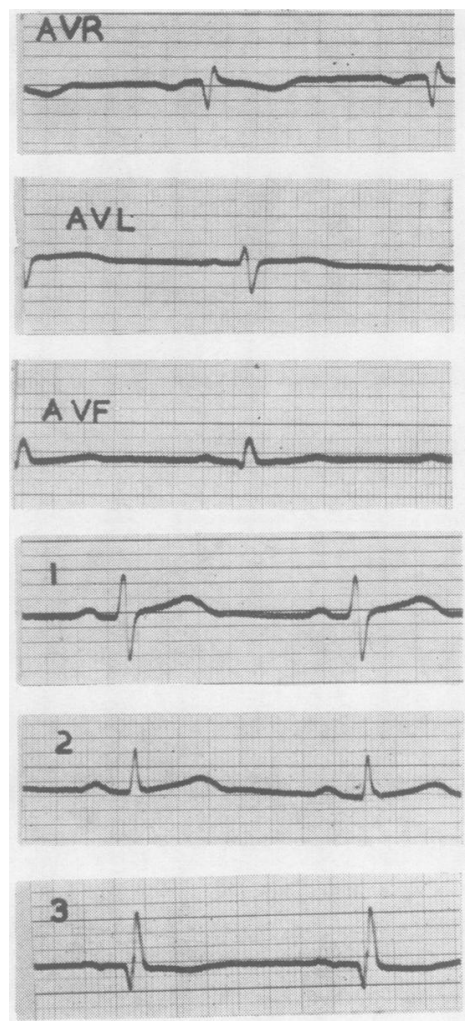

FIG. 4b

$23 / 4 / 52$
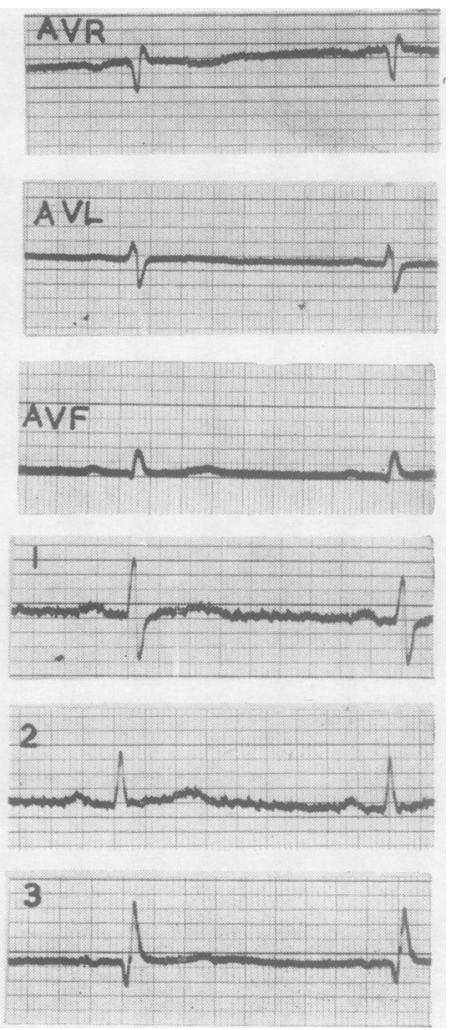

Fig. 4c

$30 / 4 ; 52$ no haemoptysis, and it would therefore seem that the lung escaped major vascular injury. It would have been anatomically possible for the blade to enter the liver, but as there were never any abnormal physical signs in the abdomen this is improbable.

The point and edges of the dagger were very sharp, and a strong thrust with it would have incised the tissues cleanly. This may have been a large factor in preventing more serious injury.

\section{SUMMARY}

A case of stab wound of the chest in a young woman with division of the right phrenic nerve and injury to the right ventricle is described. Complete recovery ensued, and radiography and E.C.G.s showed normal pictures. The pathway taken by the dagger is discussed.

We wish to thank Mr. W. D. Park, under whose care the patient was admitted, for permission to publish this case.

\section{REFERENCES}

Barrett, N. R. (1950). Brit. J. Surg., 37, 416.

Neuhöfer, P. (1922). Mitt. Grenzgeb. Medl. Chir., 35, 1.

Reichl, E. (1932). Zbl. Chir., 59, 1218. 